\title{
Development of Environment-Friendly Membrane for Oily Industrial Wastewater Filtration
}

\author{
Mohammed Alquraish ${ }^{1}$, Yong Tzyy Jeng ${ }^{2}$, Mohamed Kchaou ${ }^{1, *} \mathbb{B}$, Yamuna Munusamy ${ }^{2}$ and Khaled Abuhasel ${ }^{1}(\mathbb{D}$ \\ 1 Department of Mechanical Engineering, College of Engineering, University of Bisha, \\ Bisha 67714, Saudi Arabia; malqraish@ub.edu.sa (M.A.); kabuhasel@ub.edu.sa (K.A.) \\ 2 Department of Petrochemical Eng, Faculty of Engineering and Green Technology, Universiti Tunku Abdul \\ Rahman, Kampar 31900, Malaysia; yongtj@utar.edu.my (Y.T.J.); yamunam@utar.edu.my (Y.M.) \\ * Correspondence: kchaou.mohamed@yahoo.fr
}

check for

updates

Citation: Alquraish, M.; Jeng, Y.T.;

Kchaou, M.; Munusamy, Y.; Abuhasel,

K. Development of Environment-

Friendly Membrane for Oily

Industrial Wastewater Filtration.

Membranes 2021, 11, 614.

https://doi.org/10.3390/

membranes11080614

Academic Editor: Alessandra

Criscuoli

Received: 7 July 2021

Accepted: 6 August 2021

Published: 11 August 2021

Publisher's Note: MDPI stays neutral with regard to jurisdictional claims in published maps and institutional affiliations.

Copyright: (C) 2021 by the authors. Licensee MDPI, Basel, Switzerland. This article is an open access article distributed under the terms and conditions of the Creative Commons Attribution (CC BY) license (https:// creativecommons.org/licenses/by/ $4.0 /)$.

\begin{abstract}
Latex phase blending and crosslinking method was used in this research work to produce nitrile butadiene rubber-graphene oxide (NBR-GO) membranes. This fabrication technique is new and yields environmentally friendly membranes for oil-water separation. GO loading was varied from 0.5 to 2.0 part per hundred-part rubber (pphr) to study its effect on the performance of NBR-GO membrane. GO was found to alter the surface morphology of the NBR matrix by introducing creases and fold on its surface, which then increases the permeation flux and rejection rate efficiency of the membrane. X-Ray diffraction analysis proves that GO was well dispersed in the membrane due to the non-existence of GO fingerprint diffraction peak at $2 \theta$ value of $10-12^{\circ}$ in the membrane samples. The membrane filled with $2.0 \mathrm{pphr}$ GO has the capability to permeate $7688.54 \mathrm{Lm}^{-2} \mathrm{~h}^{-1}$ water at operating pressure of 0.3 bar with the corresponding rejection rate of oil recorded at $94.89 \%$. As the GO loading increases from 0.5 to $2.0 \mathrm{pphr}$, fouling on the membrane surface also increases from Rt value of $45.03 \%$ to $87.96 \%$. However, $100 \%$ recovery on membrane performance could be achieved by chemical backwashing.
\end{abstract}

Keywords: membrane filtration; oil-water separation; oil rejection rate; performance

\section{Introduction}

In 2015, the United Nations (UN) General Assembly recognized clean water-a critical element for all living things on this planet-as one of the sustainable development goals (SDG). However, more than eight hundred children under the age of five die every single day from water contamination, pollution, and poor sanitation. According to the World Water Council, 700 million humans will still live in water scarcity by the year 2030 [1]. This ecological crisis is the consequence of the rapid urbanization and industrialization that directly causes water pollution through the discharge of large volumes of toxic pollutants such as oils, organic solvents, dyes, toxic chemicals, microplastics, biological substances, and heavy metal ions into water body $[2,3]$. Thence, the development of effective technologies to protect our ecosystem is greatly needed at this point of time. Traditional oil from water separation methods, such as coagulation, dissolved air floatation, gravity separation, flocculation, and de-emulsification have some drawbacks, for example high operation cost, low filtration efficiency, energy consuming, complex processes, corrosion of the equipment, and recontamination. Moreover, these techniques are ineffective in separation of micron size oil in emulsion form [4,5]. Consequently, the membrane separation method has been widely recognized as an alternate approach because of its excellent flexibility, cost effectiveness, operational easiness, fairly high efficiency, and environmental benevolence [6,7]. Regrettably, the major barrier for concrete application of membrane technology in oily wastewater filtration is the fouling tendency of membrane, the trade-off effect between permeation flux, and the rejection efficiency and poor chemical resistance [8]. 
In recent times, many scholars worked expansively on ultrafiltration (UF) membranes to find a solution for the trade-off problem during filtration. For instance, Ahmad et al. [9] fabricated UF membrane using polyvinyl chloride mixed with salt-induced pluronic F127 and bentonite to solve the trade-off issue. In this work, water flux of $607.8 \mathrm{Lm}^{-2} \mathrm{~h}^{-1}$ and oil rejection rate of more than $92.8 \%$ were achieved. Ma et al. [10] employed a polyimide membrane using zeolitic imidazolate framework-8@thiolated graphene (ZIF-8GSH) to overcome this problem. This membrane could self-clean to improve permeation flux and exhibit an oil rejection rate of $99 \%$. Thus, NBR-GO membrane was also produced to overcome the trade-off problem. NBR latex was selected for membrane application because of its remarkable structural reliability and chemical resistance [11]. The mechanical properties and chemical resistance of NBR could be altered using the three-dimensional sulphide linkages in the crosslink network. However, the hydrophobic profile of NBR latex that can compromise the permeation flux is still the foremost concern in membrane filtration technology. Therefore, our aim is to introduce water affinity into the NBR membrane by incorporating GO with oxygen functional groups, such as epoxy, carboxyl, carbonyl, and hydroxyl, on its basal planes and sheet edges [12-14]. Apart from that, GO was proposed for membrane fabrication due to its distinctive properties, such as a high surface area, hydrophilic nature, good compatibility with polymers $[15,16]$, increased resistance towards fouling, improved separation efficiency, and ability to impart excellent tensile strength to the membrane $[17,18]$. In the work done by Alammar et al., incorporation of $1 \mathrm{wt} \% \mathrm{GO}$ into polybenzimidazole membrane had caused oil rejection up to $99.9 \%$ with permeation flux of $91 \mathrm{~L} \mathrm{~m}^{-2} \mathrm{~h}^{-1} \mathrm{bar}^{-1}$. The membrane was prepared using a phase inversion method with dimethylacetamide as solvent [19]. The addition of GO from 0.05 to $0.2 \mathrm{wt} \%$ in the polysulfone membrane improved water permeability by $97 \%$ with oil rejection up to $97.9 \%$. The improvement in water permeability is achieved by reduction of water contact angle from $77^{\circ}$ due to the hydrophobic nature of polysulfone to around $65^{\circ}$ [20]. In another work using polyvinyl chloride as membrane material, the addition of GO imparted hydrophilicity to the membrane by reducing the contact angle of the membrane with water. The reduction in contact angle with incorporation of GO is due to the large amount of hydrophilic functional groups in GO, which enhances the affinity of PVC membranes towards water molecules [21].

There are plenty of reported methods in the literature to produce polymer-based membranes. For instance, stretching [22], sintering [23,24], phase inversion [25,26], and tracking etching $[27,28]$. However, all these techniques are time consuming, involve many steps, yield poor dispersion of GO, and might include large usage of non-environmentally friendly solvents, such as methyl ether ketone (MEK), tetrahydrofuran (THF), and chlorobenzene [29-31]. Gao et al. had produced cellulose modified polyvinylidene fluoride membrane using a simple, facile, and environmentally friendly method but nearly $10 \mathrm{~h}$ of laboratory preparation time is required for the membrane, which includes chemical preparations, preparation of dope solutions, coatings, and drying [32]. Therefore, a cost effective, sustainable, and environmentally friendly method is required for commercial production of polymer membrane [33].

In this research, NBR-GO membranes were produced through latex phase blending and crosslinking method, whereby the membrane could be produced in less than three hours in the laboratory through a water-based process. GO is anticipated to disperse well because the blending is carried out in the aqueous phase of the emulsion of latex. It could further promote the dispersion of hydrophilic functional groups containing GO.

Fabrication of membrane using latex phase blending and crosslinking is a new method and thus each parameter involved needs to be studied to optimize membrane performance. Therefore, the effect of GO loading on tensile properties, morphology, and performance of the membrane is evaluated and reported in this paper. These findings are crucial for optimized practical application of NBR-GO membrane in oily wastewater separation. 


\section{Materials and Methods}

\subsection{Materials}

NBR latex was supplied by Synthomer, Kulang, Johor, Malaysia. The total solid content (TSC) was calculated to be $65.70 \%$ and the molecular weight is $17.20 \times 10^{4} \mathrm{~g} / \mathrm{mol}$. Crosslinking chemicals such as sulphur (S), zinc oxide $(\mathrm{ZnO})$, zinc mercaptobenzothiazole (ZMBT), and zinc diethyldithiocarbamate (ZDEC) were in the slurry form with TSC values of $49.41 \%, 56.02 \%, 54.86 \%$, and $54.42 \%$ respectively. All these crosslink chemicals were supplied by Zarm Scientific \& Supplies, Bukit Mertajam, Penang Malaysia. Graphene oxide (GO) was purchased from GO Advanced Solutions, Bangi, Selangor, Malaysia. A single layer of GO has an average length of $873.5 \pm 141.1 \mathrm{~nm}$ and thickness of 1-2 nm.

\subsection{Production of NBR-GO Membranes}

Firstly, GO suspension with TSC value of $2 \%$ was prepared by mixing $0.2 \mathrm{~g}$ of GO with $10 \mathrm{~g}$ of deionized water. The suspension was ultra-sonicated for one hour with a probe-type QSonica ultrasonic homogenizer model Q500 supplied by Gaia Scientific, Puchong, Selangor, Malaysia. This step is carried out to separate the GO sheets that tend to adhere to each other and form aggregates. Weak Van der Waals forces hold the GO sheets in an ordered, stacked structure. A homogenous slurry was obtained and used in latex compounding for membrane production. Selected quantities of blending recipes in parts per hundred-part of rubber (pphr) consisting of 100 pphr NBR latex, 1.0 pphr of $\mathrm{ZnO}$ and ZDEC each, $0.5 \mathrm{pphr} \mathrm{ZMBT}$, GO loading varied as 0.5, 1.0, 1.5, and $2.0 \mathrm{pphr}$, and lastly, 1.0 pphr sulphur was added into a beaker. The amount of compounding chemicals was chosen based on previous reported works on NBR latex film productions [34,35]. The compound was then stirred at a speed of $350 \mathrm{rpm}$ for $30 \mathrm{~min}$ with IKA overhead stirrer model EUROSTAR Digital 20 supplied by IKA Works Asia, Rawang, Selangor, Malaysia. The compounds were casted into NBR-GO membranes with the thickness of $0.1 \mathrm{~mm}$ on glass plates with a laboratory size membrane auto casting machine, model A4K-S564 from Autonics, Malaysia. A distance of $220 \mathrm{~mm}$ and a forward speed of $150 \mathrm{rpm}$ was used to cast the membranes. The casted membranes on the glass plate were crosslinked in a conventional oven model Memmert supplied by Interscience, Shah Alam, Selangor, Malaysia at temperature $100{ }^{\circ} \mathrm{C}$ for $2 \mathrm{~h}$. The formulation used for membrane production and its designations are summarized in Table 1.

Table 1. Formulation for membrane production.

\begin{tabular}{cccccc}
\hline $\begin{array}{c}\text { Sample } \\
\text { Designation }\end{array}$ & NBR & NBR-GO 0.5 & NBR-GO 1.0 & NBR-GO 1.5 & NBR-GO 2.0 \\
\hline Materials & \multicolumn{5}{c}{ (pphr) } \\
\hline NBR & 100 & 100 & 100 & 100 & 100 \\
ZnO & 1.0 & 1.0 & 1.0 & 1.0 & 1.0 \\
ZDEC & 1.0 & 1.0 & 1.0 & 1.0 & 1.0 \\
ZMBT & 0.5 & 0.5 & 0.5 & 0.5 & 0.5 \\
GO & 0 & 0.5 & 1.0 & 1.5 & 2.0 \\
KOH & 1.0 & 1.0 & 1.0 & 1.0 & 1.0 \\
Sulfur & 1.0 & 1.0 & 1.0 & 1.0 & 1.0 \\
\hline
\end{tabular}

\subsection{Characterization of the Membranes}

The membrane's surface morphology was observed under a field emission scanning electron microscope (FESEM), model JEOL JSM 6710F, supplied by JEOL USA Inc., Peabody, MA, USA. In order to enhance the electron charging during image processing, all the membranes were sputter-coated with platinum particles prior to scanning. Functional groups on the membrane surface were determined using Fourier-transform infrared (FTIR) spectroscopy. The analysis was carried out using attenuated total reflectance (ATR) technique at room temperature between the wavelength of 400 and $4000 \mathrm{~cm}^{-1}$ using Spectrum RX1 Perkin Elmer Analyzer supplied by Perkin Elmer Sdn. Bhd Petaling Jaya, Selangor, 
Malaysia. Dispersion of GO in the membranes was characterized using X-ray diffraction (XRD) analysis using Siemens XRD Diffractometer Model 5000 supplied by DKSH Technology Sdn. Bhd., Petaling Jaya, Selangor, Malaysia. The diffractometer operates using nickel-filtered copper $\mathrm{K}_{\alpha}$ radiation with $\lambda=0.154 \mathrm{~nm}$. Parameters of the analysis includes step scan with scanning rate of $2^{\circ} / \mathrm{min}$ between the scanning angles of 10 and $60^{\circ}$. Crosslink density of each membrane were determined using the methodology in our previous publication [36]. Five samples were used for each membrane category and an average crosslink density value was calculated from the samples.

\subsection{Performance Studies}

The ultimate tensile strength (UTS), E-modulus (E), and percentage of elongation at break $(\% \mathrm{~EB})$ of the membranes were determined using the tensile test. For each membrane composition, seven dumbbell-shaped samples were prepared, and the average value of each test result was calculated. Each sample had a gauge length of $26 \mathrm{~mm}$ and a neck width of $3 \mathrm{~mm}$. Tensile test was performed following ASTM D882-10 standard, with a load setting of $450 \mathrm{~N}$ and a pulling speed of $100 \mathrm{~mm} / \mathrm{min}$ using a light-weight tensile tester, model H10KS-0748 from Tinius Olsen Ltd., Redhill, UK, supplied by Leader Technology Scientific (M) Sdn. Bhd., Seri Kembangan, Selangor, Malaysia.

Dead-end membrane test rig supplied by Shxp Trading, Bandar Tasek Selatan, Selangor, Malaysia, was used to carry out the permeation flux test at the operating pressure between $0.1-0.3$ bar. Emulsified oily wastewater with an oil content of $1000 \mathrm{ppm}$ was prepared in the laboratory by emulsifying diesel with $0.01 \mathrm{wt} \%$ of sodium dodecyl sulphate (SDS) in deionized water for $30 \mathrm{~min}$ using a probe-type QSonica ultrasonic homogenizer model Q500. The size of the oil particles was determined using a Lighthouse liquid particle counter, model LS-20 supplied by Lighthouse Worldwide Solution (M) Sdn. Bhd., George Town, Penang, Malaysia. The size fell within a range of 1.0-50 $\mu \mathrm{m}$ with the majority of particle size is at $6 \mu \mathrm{m}$. The permeation flux was calculated using Equation (1). Thirty $\mathrm{mL}$ permeate was collected for each run and the time taken was recorded. The diameter of the membranes used for filtration cell was fixed to $50 \mathrm{~mm}$ to provide effective area for permeation of $1.0179 \times 10^{-3} \mathrm{~m}^{2}$. Five membrane samples from each category were used for the test and the average permeation flux was calculated.

$$
J=\frac{V_{p}}{A \times t}
$$

where:

$J=$ Permeation flux, $\frac{L}{m^{2} \cdot h r}$

$V_{p}=$ Permeate volume collected, $L$

$A=$ Effective membrane area, $m^{2}$

$t=$ Time taken to collect the measured volume of permeate, $h r$

Oil rejection efficiency of the membranes was assessed by performing chemical oxygen demand (COD) analysis on the filtrate from permeation flux test. Five filtrate samples were used for each membrane category. HACH COD vials and a HACH COD digester were used for digestion of the filtrate and the COD value was recorded using HACH DR6000 UV-VIS spectrophotometer. The oil rejection efficiency was then calculated based on Equation (2).

$$
R=\left(1-\frac{C O D_{p}}{C O D_{f}}\right) \times 100 \%
$$

where:

$R=$ Oil rejection efficiency, \%

$C O D_{p}=$ COD level in permeate, $\mathrm{mg} / \mathrm{L}$

$C O D_{f}=$ COD level in feed, $\mathrm{mg} / \mathrm{L}$ 
The total fouling ratio $\left(R_{t}\right)$ and flux recovery ratio (FRR) of the membranes were determined at the constant operating pressure of 0.1 bar using Equations (3) and (4), respectively [37]. Firstly, water flux for clean deionized water was measured as $J_{w 1}$, the flux of 1000 ppm synthetic oily wastewater as $J_{p}$; after that, the membrane was cleaned by rinsing with clean water at room temperature and the water flux was recorded as $J_{w 2}$. For comparison, the backflushing technique was also applied in the membrane cleaning for $1 \mathrm{~min}$ [38]. These values are an indicator for the antifouling performance. Membranes with low $R_{t}$ and high FRR values would have excellent fouling resistance. Five samples were used for each membrane category and the average $R_{t}$ and FRR values had been reported.

$$
\begin{aligned}
& R_{t}=\left(\frac{J_{w 1}-J_{p}}{J_{w 1}}\right) \times 100 \% \\
& F R R=\left(\frac{J_{w 2}}{J_{w 1}}\right) \times 100 \%
\end{aligned}
$$

where:

$J_{p}=$ Permeation flux of synthetic oily wastewater

$J_{w 1}=$ Permeation flux of deionized water

$J_{w 2}=$ Permeation flux of deionized water after membrane cleaning

\section{Results}

\subsection{Characterization of the Membrane}

NBR-GO membranes demonstrate a clear wrinkled and folded structure as shown in Figure 1. This kind of structure is attributed to the unevenly distributed oxygen functional groups of GO that produce the folding and notching effect of GO sheets edges on the NBR membrane surface during casting. The low-density GO moves up towards the membrane surface during the crosslinking process. Ridged, scrolled, and creased surface on the membranes create folds, edges, and channels which can increase the effective surface area for oily wastewater UF. Consequently, improvement in permeation flux and oil rejection efficiency are expected. Creation of folds on the membrane surfaces filled with GO were also reported in other works [2,39-41]. Some macropores could also be observed on the surfaces of membranes with 0.5 and 1.0 pphr GO loadings. These pores could not be observed on membranes with higher GO loadings because the surfaces are covered with GO. The existence of pores also did not increase the water flux compared to membranes with 1.5 and 2.0 pphr GO loading which indicates the dominance of GO nanosheets surface structures and hydrophilicity on water molecule affinity and permeability.

The creases and folds are getting more prominent as the GO loading increases and this has proven more movement of GO sheets to the surface of the membrane during casting and crosslinking steps. The channels between the ridges on the membrane can allow the oil particles to be trapped in the grooves of the membrane, and hence, high oil rejection could be achieved. However, as the GO loading increases, more wrinkles and ridges directly cause the groove width to be narrower, consequently, the bigger oil droplets are likely to recess and clog the membrane. As such, the higher possibility for membrane fouling occurs with higher GO loading. On the other hand, GO, which acts as the additives in the UF membrane, is hydrophilic in nature due to its oxygen functional group, and hence, this significantly increases the permeation flux performance as the GO loading increases. Figure 2 presents the FTIR spectrum of NBR and the NBR-GO membranes. 


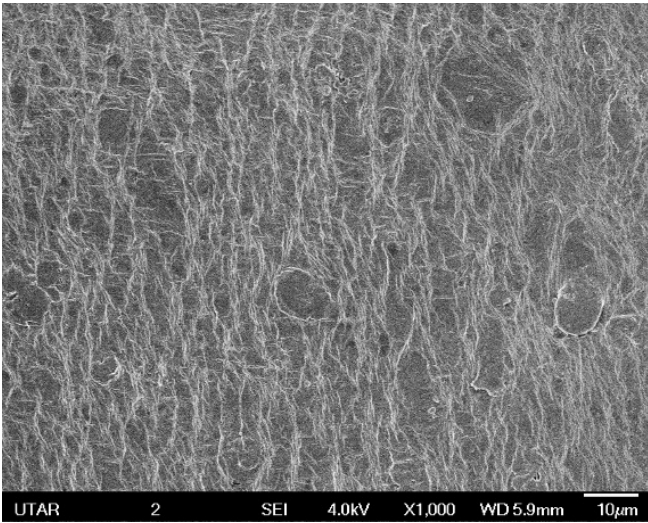

(a)

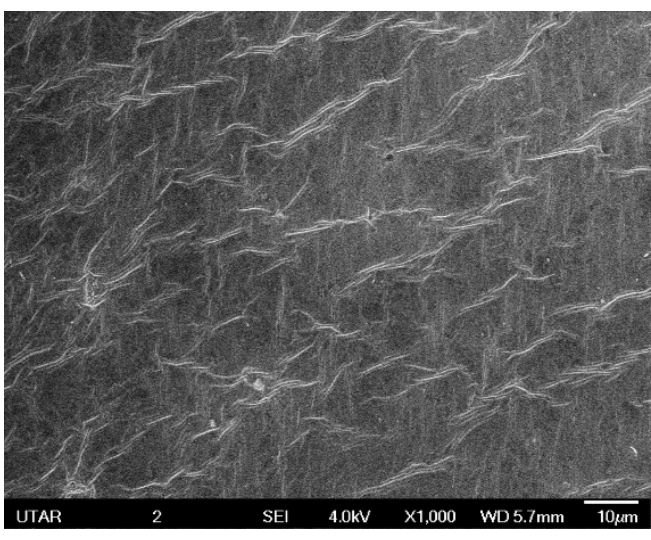

(c)

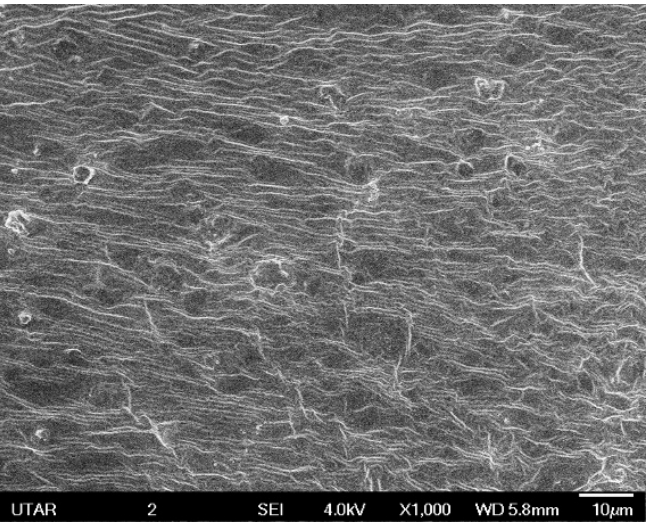

(b)

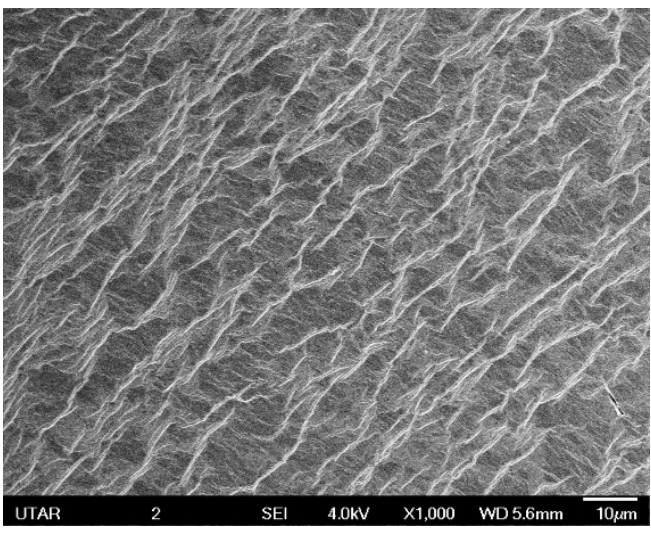

(d)

Figure 1. SEM observations of the NBR-GO membrane surfaces. (a) 0.5 pphr GO. (b) 1.0 pphr GO. (c) 1.5 pphr GO. (d) 2.0 pphr GO.

The peak at $3400 \mathrm{~cm}^{-1}$ indicates the existence of the $\mathrm{O}-\mathrm{H}$ functional group from the surface-bounded $\mathrm{H}_{2} \mathrm{O}$ molecules. The peaks at $2237 \mathrm{~cm}^{-1}, 1641 \mathrm{~cm}^{-1}$, and $1559 \mathrm{~cm}^{-1}$ are apportioned to the $\mathrm{C} \equiv \mathrm{N}$ groups, $\mathrm{C}=\mathrm{C}$ bonds and $\mathrm{N}-\mathrm{H}$ bending of NBR, respectively [42]. The peak at $1442 \mathrm{~cm}^{-1}$ confirms the occurrence of carboxylic acid O-H stretching while C-O bending is denoted by $969 \mathrm{~cm}^{-1}$ peak [43]. The bands between $917 \mathrm{~cm}^{-1}$ to $699 \mathrm{~cm}^{-1}$ specify the occurrence of S-OR and S-S disulphide stretching of sulphur crosslinked system in the NBR polymer matrix. No new peak was observed; thus, it can be deduced that the NBR and GO are interacted physically and not chemically. The NBR polymer chains could be adsorbed or entrapped on the surface of GO which creates a good fillermatrix interphase.

XRD analysis was performed to evaluate the dispersions of GO nanosheets in the NBR membrane and presented in Figure 3. The ordered intercalated structure of GO nanosheets is represented by the sharp and strong peak found at $2 \theta$ value of $10-12^{\circ}$ which is the characteristic diffraction peak for GO [44]. The GO nanosheets are intercalated due to the presence of oxygen functional groups such as carboxyl, carbonyl, epoxide, and hydroxyl which adhere to the edges and basal planes of GO sheets. Typically, 6-7 graphene layers will heap together to form the GO nanostructure. A broad diffraction peak is shown in the pure NBR membrane, representing that the pure NBR is a non-crystalline structure. For the XRD diffraction of all NBR/GO membranes, no GO characteristic peak could be distinguished, and it can be concluded that there is no layer-by-layer restack of GO in the NBR matrix, thus the homogenous dispersion state of GO in NBR matrix is proposed [45]. NBR polymer chains could penetrate between the GO layers and exfoliate the layers, thus destroying the ordered intercalated structure of GO. 


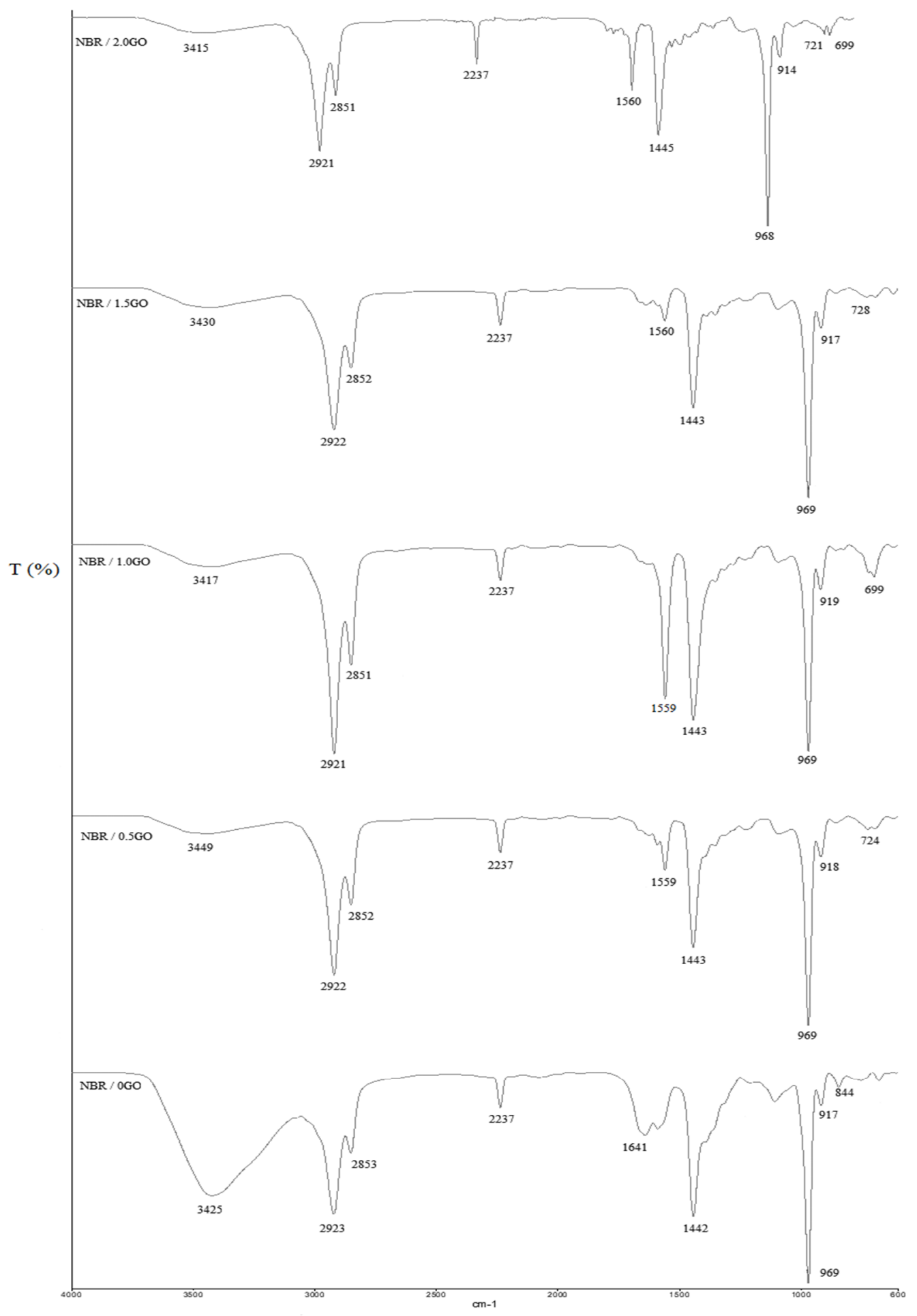

Figure 2. FTIR spectra for pure NBR and NBR-GO membranes at different GO loadings. 


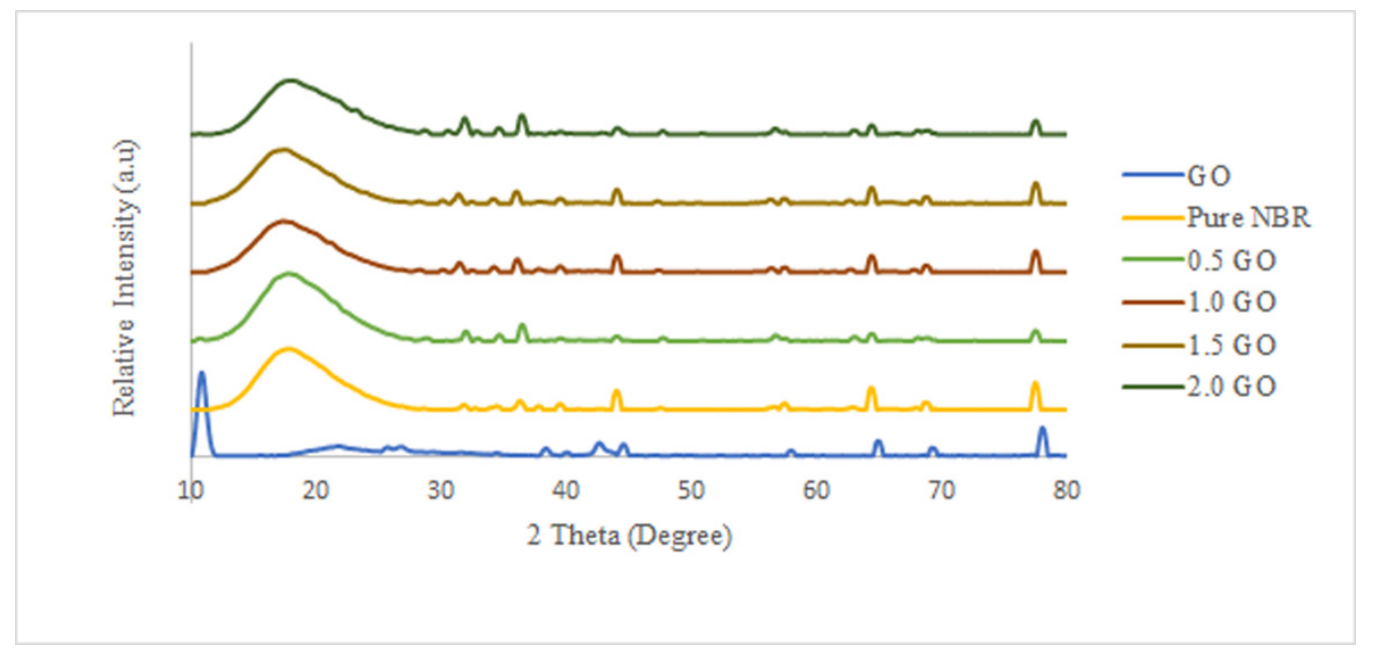

Figure 3. XRD pattern of GO, Pure NBR, and NBR-GO membranes at different GO loadings.

All the membranes contain $1.0 \mathrm{pphr}$ sulphur and are being crosslinked at the same temperature and time duration. Crosslinks form a stable three-dimensional sulphide network between the NBR polymeric chains. These linkages impart high mechanical strength and chemical resistance to the membrane. The crosslink density in each membrane is shown in Table 2. GO loading was found not to influence the crosslink density as the crosslink density between all the samples was almost similar to one another.

Table 2. Crosslink density of the membranes.

\begin{tabular}{cc}
\hline GO Loading $(\mathbf{p p h r})$ & Crosslink Density $\left(\times \mathbf{1 0}^{-\mathbf{4}} \mathbf{~} \mathbf{m o l} / \mathbf{c m}^{\mathbf{3}}\right)$ \\
\hline 0 & $9.1037 \pm 0.0038$ \\
0.5 & $9.0525 \pm 0.0018$ \\
1.0 & $9.2729 \pm 0.0045$ \\
1.5 & $9.1366 \pm 0.0063$ \\
2.0 & $9.0754 \pm 0.0025$ \\
\hline
\end{tabular}

\subsection{Performance Study}

\subsubsection{Tensile Properties}

The UTS, E-modulus and EB\% are shown in Figures 4-6. All the membranes filled with GO showed higher UTS compared to pure NBR membrane with optimum increment of UTS achieved at $0.5 \mathrm{pphr}$ GO loading. GO has strong mechanical reinforcing effect to the NBR polymer matrix due to excellent interfacial physical interaction between the GO and NBR matrix [46]. This interaction is promoted by the high surface area of dispersed GO sheets. As the GO loading increases, there will more concentration of GO on the surface of the membranes as suggested by the creases and folds in SEM images that caused the demobilization effect of polymeric chain, causing a decrease in UTS of the membranes. The $\mathrm{EB} \%$ of the membranes show similar trend with UTS. Improvement of EB with addition of fillers confirms strong interfacial interaction between the filler and matrix, thus when subjected to tension the filler and matrix acts as a synergistic system and elongate in the direction of load without detachment of the fillers from the matrix [47]. The modulus of the membrane increases more than $200 \%$ at $0.5 \mathrm{pphr}$ GO loading compared to pure NBR but then does not show any significant improvement compared to modulus of pure NBR at GO loading between 1 to $2.0 \mathrm{pphr}$. 


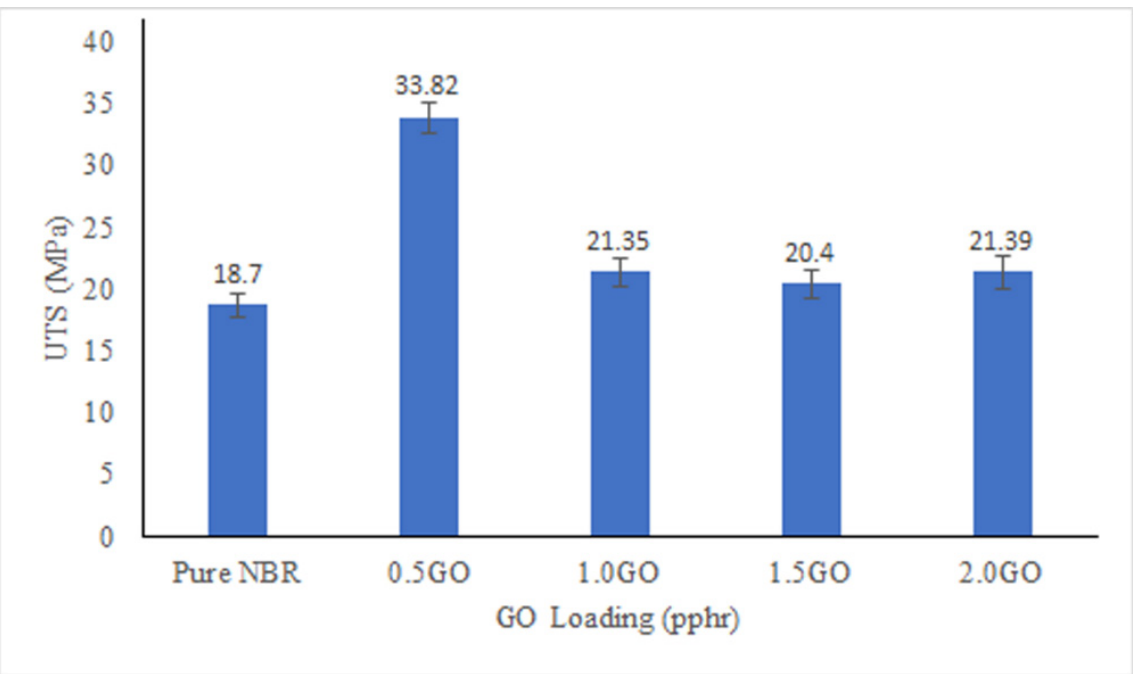

Figure 4. Ultimate tensile strength (UTS) of the membranes with different GO loading.

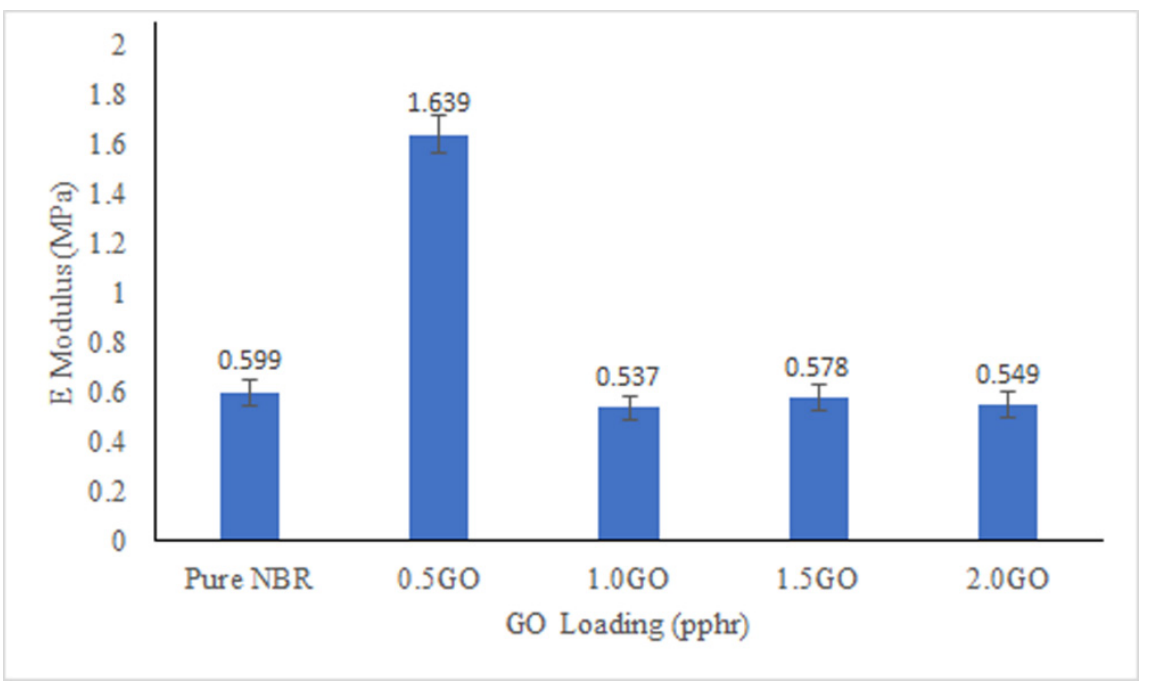

Figure 5. E-modulus of the membranes at different GO loading.

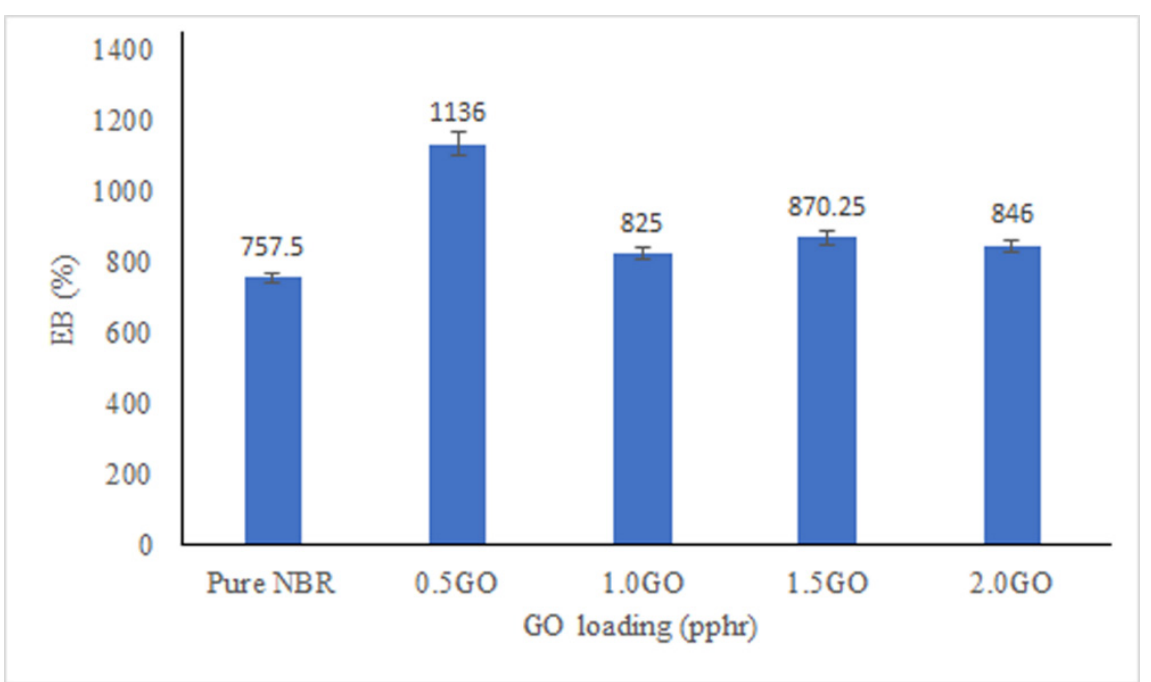

Figure 6. Elongation at break of the membranes at different GO loading. 


\subsubsection{Permeation Flux}

The permeation flux of NBR-GO membranes strongly relies on its microstructure and morphology. Influence of different GO loading on the permeation flux performance of the membranes is shown in Figure 7. It is understood that the pure NBR membrane did not show any permeation flux because of the hydrophobic characteristic of NBR polymer matrix. Therefore, the inclusion of GO into the NBR matrix results in the permeability of the membranes [48]. As evidenced from the Figure 7, the membranes permeability increases from 394.4 .3 to $3132.59 \mathrm{~L}^{2} \mathrm{~m}^{-2} \mathrm{~h}^{-1}, 980.51$ to $6381.94 \mathrm{~L}^{2} \mathrm{~m}^{-2} \mathrm{~h}^{-1}$, and 2206.30 to $7688.54 \mathrm{~L}^{2} \mathrm{~m}^{-2} \mathrm{~h}^{-1}$ at $0.1,0.2$, and 0.3 bar, respectively. This is because the higher the GO loading, the more wrinkles have formed on the membranes as shown by SEM images. This directly generates more effective areas for the UF to occur.

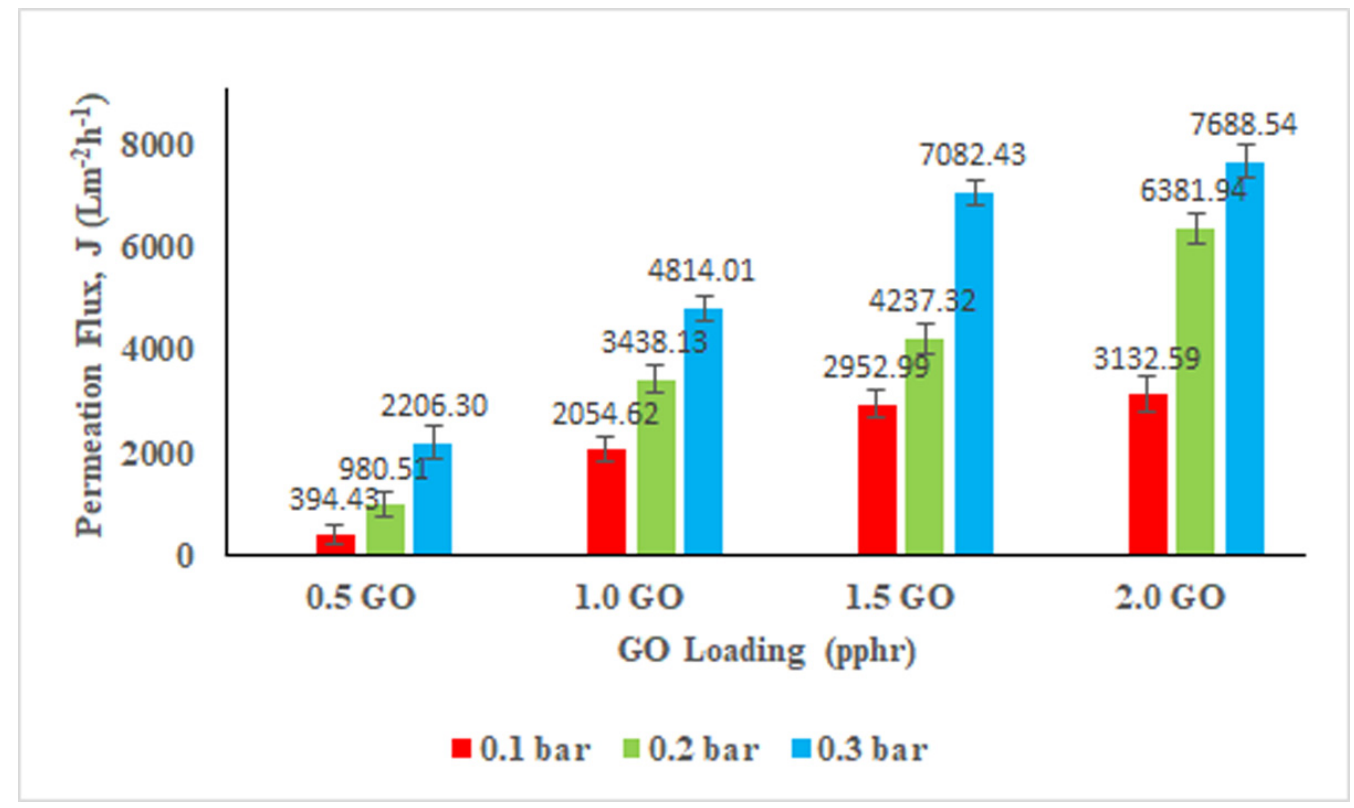

Figure 7. Permeation flux of the membranes tested at different operating pressure.

The permeation flux in the system escalates proportionally with increment in operating pressure. At higher value of operating pressure, the water droplets can readily permeate through the membrane because of the higher driving force which pushes the droplets across the membrane [49]. As compared to the other literature, NBR-GO membranes can have a high permeation flux performance at a low operating pressure of $0.1-0.3 \mathrm{bar}$ and this has proven that the membrane is considerably cheaper in terms of energy and cost. Even though the permeation flux of NBR-GO membranes is exceptional, selection of the right composition of the membrane is ultimately depended on the oil rejection efficiency. This performance is critical since the governing body requisite on allowable oil content in treated wastewater to be discharged in water body must be fulfilled.

\subsubsection{Oily Rejection Efficiency of NBR-GO Membranes}

Figure 8 shows that the least oily wastewater rejection efficiency for the membranes with different GO was recorded at $92.35 \%$. This high rejection efficiency is mainly attributed to the wrinkles and the grooves between the ridges on the membrane that can trap the oil particles in the grooves of the membrane. As higher operating pressure is being applied, accumulation of oil droplets on the membrane surface starts to happen and eventually a thin layer of oil films will be formed. These will turn to be a blockade for the passage of other oil droplets in the water during filtration. Nevertheless, the relationship between operating pressure and oil rejection efficiency is not proportional [50]. Consequently, 2.0 pphr GO filled NBR membrane is more desirable because it has the highest permeation flux at any operating pressure and high oil rejection efficiency of up to $95.7 \%$. Furthermore, 
it has successfully fulfilled the global oil discharge limit with the maximum allowable oil concentration of $72 \mathrm{mg} / \mathrm{L}$ for any 24-h period set by the Environmental Protection Agency (EPA), the United States [51]. However, in future work the oil rejection could be further improved by modification of $\mathrm{GO}$ with more hydrophilic functional groups and formation of coating layer on the surface of the membrane.

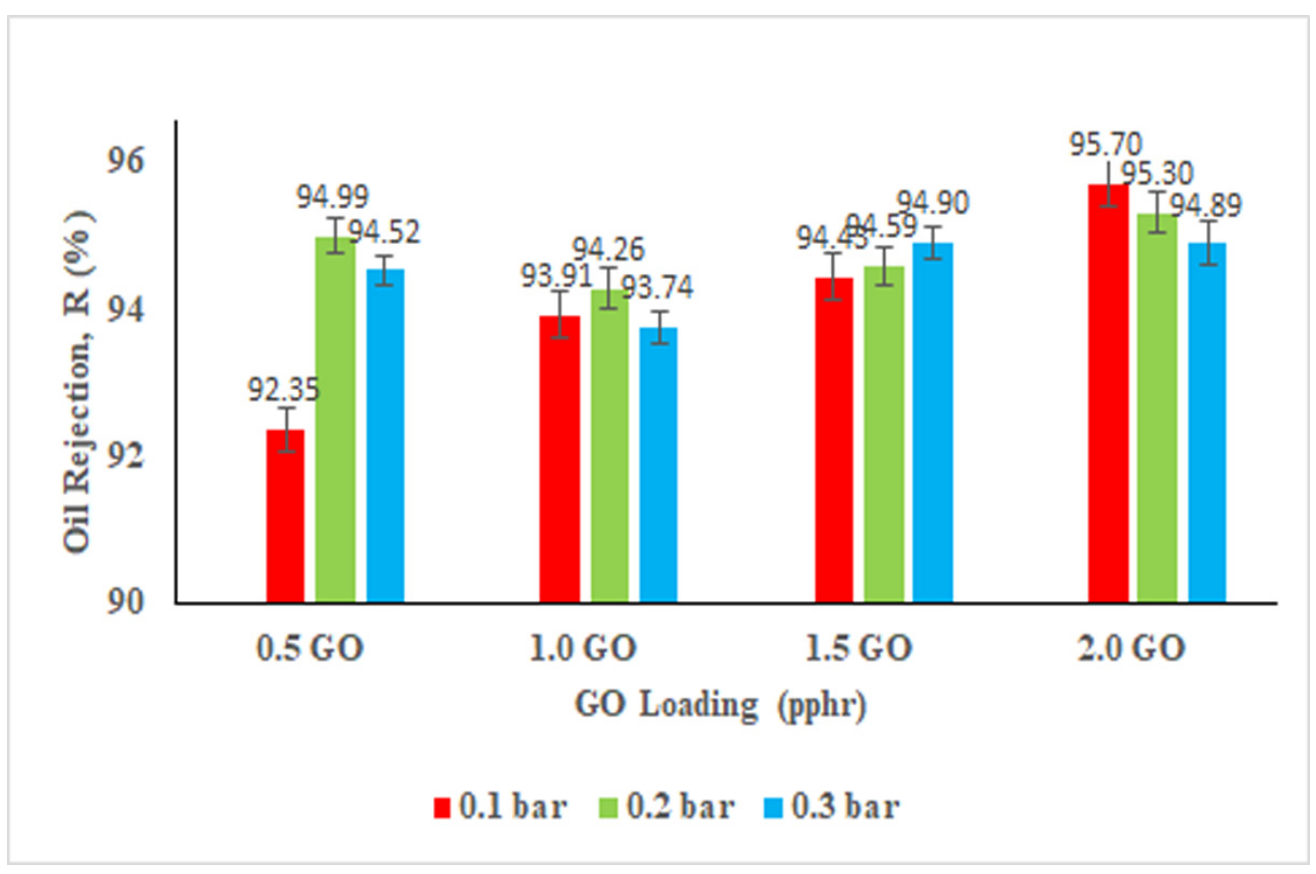

Figure 8. Oil rejection (\%) of the membranes at different operating pressures.

The results obtained from this study using the NBR-GO flat sheet membranes are comparable or even better than previous reported research works. One $w t \%$ GO filled polyether sulfone flat sheet membrane produced by Junaidi et al., shows rejection rate of oil around $50 \%$ and water flux of $95.12 \pm 8.51 \mathrm{Lm}^{-2} \mathrm{~h}^{-1}$ at pressure $1 \mathrm{bar}$ [40]. Meanwhile in another study by Amid et al., $0.25 \mathrm{wt} \%$ GO filled polycarbonate flat sheet membrane shows $99 \%$ rejection rate of oil with water flux of $85.85 \mathrm{Lm}^{-2} \mathrm{~h}^{-1}$ at operating pressure of 2 bar [52]. Isotactic propylene-polydopamine-GO membrane shows an oil rejection rate of more than $99 \%$ but the corresponding water flux is only recorded at $188 \mathrm{Lm}^{-2} \mathrm{~h}^{-1}$ at an operating pressure of $0.1 \mathrm{MPa}$ [53].

\subsubsection{Antifouling Properties}

The fouling and antifouling performance of the membranes were evaluated by $R_{t}$ and FRR, respectively, after the filtration of the oily wastewater, and the results are shown in Figure 9. It can be found that the $2.0 \mathrm{pphr}$ GO filled membrane has the highest $\mathrm{R}_{\mathrm{t}}$ of $87.96 \%$ and the $0.5 \mathrm{pphr}$ GO filled membrane has the lowest $\mathrm{R}_{\mathrm{t}}$ of $45.03 \%$. This is due to the foulants in terms of bigger oil particle size and the SDS that can form filter-cake-layers on the membrane, fasten the fouling rate and result in a very serious $R_{t}$. Nevertheless, membrane fouling is very common to all membranes regardless of commercial line or research line.

To confirm that the membranes can be recycled, the antifouling performance through FRR is carried out. As shown in Figure 9, normal rinsing with water at room temperature can only recover $41.23 \%, 38.10 \%, 34.88 \%$, and $29.25 \%$ for $0.5 \mathrm{GO}, 1.0 \mathrm{GO}, 1.5 \mathrm{GO}$, and 2.0 GO filled NBR membrane, respectively. This may be due to the normal washing method that could not wash off the oil particle and the SDS on the membrane fully. On the other hand, the membranes can be fully recovered using the back-flushing method. This method applies higher pressure on the permeate side of the membrane, in so doing 
causing backward movement of the permeate through the membrane [54]. Backwashing is the furthermost broadly employed fouling reversal technique used in industry [2].

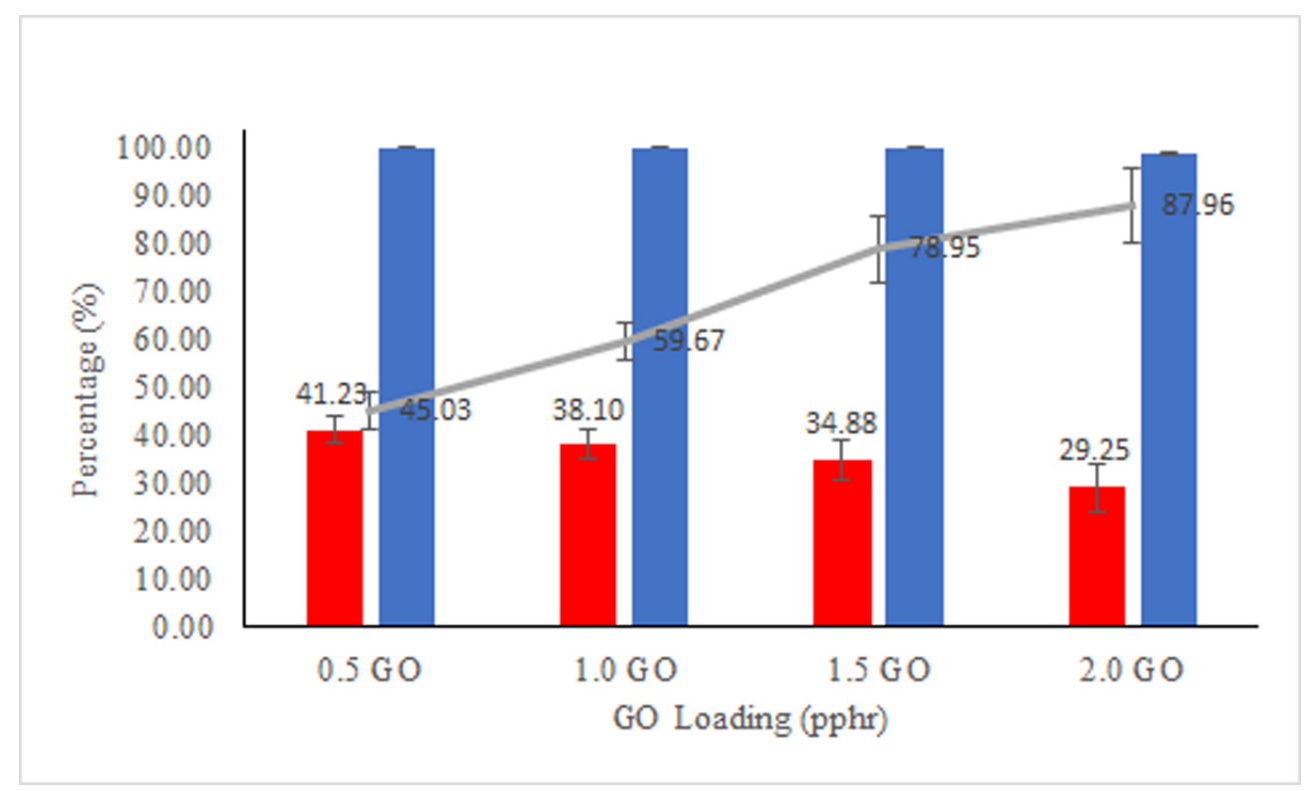

Figure 9. FRR (normal rinsing) שـ, FRR (back flushing) _ and Rt _— values of the membranes.

There are so many membrane cleaning methods reported in the literature: pneumatic cleaning $[55,56]$, ultrasonic cleaning $[57,58]$, sponge ball cleaning $[59,60]$, and chemical cleaning $[61,62]$ However, backflushing is the most accessible and cheaper technique to obtain maximum recovery among all. Anyhow, the effect of membrane cleaning methods on the NBR-GO membrane will be evaluated in the next study.

\section{Conclusions}

NBR-GO membranes were produced successfully using the latex compounding and crosslinking method. This production method is water based and requires approximately $2 \mathrm{~h}$ laboratory preparation time. NBR membrane with $2.0 \mathrm{pphr}$ GO loading has shown the highest oil rejection efficiency of $95.70 \%$ with corresponding permeation flux of $3132.59 \mathrm{Lm}^{-2} \mathrm{~h}^{-1}$ at pressure 0.1 bar. The obtained rejection efficiency fulfils the standard for treated oily wastewater discharge. It is also noteworthy that the obtained permeation flux is high for a flat sheet membrane compared to the ones reported in literature. However, based on the total fouling ratio study, the membrane with $2.0 \mathrm{pphr}$ GO faced a serious fouling problem and normal rinsing it not sufficient to recover its performance. The problem could be solved with the backflushing method. These results provide a window to consider crosslinked elastomeric materials for membrane fabrication using the cost effective and environmentally friendly latex compounding method.

Author Contributions: Conceptualization, M.K. and Y.M.; methodology, Y.M.; software, Y.T.J.; validation, M.K., M.A. and Y.M.; formal analysis, Y.M.; investigation, M.K.; resources, Y.T.J.; data curation, Y.T.J.; writing—original draft preparation, Y.M.; writing—review and editing, M.K. and M.A.; visualization, M.A.; supervision, K.A.; project administration, M.A. and K.A.; funding acquisition, M.A. All authors have read and agreed to the published version of the manuscript.

Funding: This research received no external funding.

Institutional Review Board Statement: Not applicable.

Informed Consent Statement: Not applicable.

Data Availability Statement: Not applicable. 
Acknowledgments: The authors extend their appreciation to the Deputyship for Research \& Innovation, Ministry of Education in Saudi Arabia for supporting scientific research.

Conflicts of Interest: The authors declare no conflict of interest.

\section{References}

1. Abuhasel, K.; Kchaou, M.; Alquraish, M.; Munusamy, Y.; Jeng, Y.T. Oily wastewater treatment: Overview of conventional and modern methods, challenges, and future opportunities. Water 2021, 13, 980. [CrossRef]

2. Ezugbe, E.O.; Rathilal, S. Membrane technologies in wastewater treatment: A review. Membranes 2020, 10, 89. [CrossRef] [PubMed]

3. Ma, W.; Li, Y.; Gao, S.; Cui, Y.; Qu, Q.; Wang, Y.; Huang, C.; Fu, G. Self-healing and superwettable nanofibrous membranes with excellent stability toward multifunctional applications in water purification. ACS Appl. Mater. Interfaces 2020, 12, 23644-23654. [CrossRef] [PubMed]

4. Yan, L.; Hong, S.; Li, M.L.; Li, Y.S. Application of the Al2O3-PVDF nanocomposite tubular ultrafiltration (UF) membrane for oily wastewater treatment and its antifouling research. Sep. Purif. Tech. 2009, 66, 347-352. [CrossRef]

5. Ma, W.; Ding, Y.; Zhang, M.; Gao, S.; Li, Y.; Huang, C.; Fu, G. Nature-inspired chemistry toward hierarchical superhydrophobic, antibacterial and biocompatible nanofibrous membranes for effective UV-shielding, self-cleaning and oil-water separation. J. Hazard. Mat. 2020, 384, 121476. [CrossRef]

6. $\quad$ Ma, W.; Zhao, J.; Oderinde, O.; Han, J.; Liu, Z.; Gao, B.; Xiong, R.; Zhang, Q.; Jiang, S.; Huang, C. Durable superhydrophobic and superoleophilic electrospun nanofibrous membrane for oil-water emulsion separation. J. Col. Interf. Sci. 2018, 532, 12-23. [CrossRef] [PubMed]

7. Zarghami, S.; Mohammadi, T.; Sadrzadeh, M.; Van der Bruggen, B. Bio-inspired anchoring of amino-functionalized multi-wall carbon nanotubes (N-MWCNTs) onto PES membrane using polydopamine for oily wastewater treatment. Sci. Total Environ. 2020, 711, 134951. [CrossRef] [PubMed]

8. Park, H.B.; Kamcev, J.; Robeson, L.M.; Elimelech, M.; Freeman, B.D. Maximizing the right stuff: The trade-off between membrane permeability and selectivity. Science 2017, 356, 1. [CrossRef]

9. Ahmad, T.; Guria, C.; Mandal, A. Enhanced performance of salt-induced pluronic F127 and bentonite blended polyvinyl chloride ultrafiltration membrane for the Processing of oilfield produced water. J. Water Proc. Eng. 2020, 34, 101144. [CrossRef]

10. Ma, W.; Li, Y.; Zhang, M.; Gao, S.; Cui, J.; Huang, C.; Fu, G. Biomimetic durable multifunctional self-cleaning nanofibrous membrane with outstanding oil/water separation, photodegradation of organic contaminants, and antibacterial performances. ACS Appl. Mater. Interf. 2020, 12, 34999-35010. [CrossRef] [PubMed]

11. Zhang, Z.; Sun, J.; Lai, Y.; Wang, Y.; Liu, X.; Shi, S.; Chen, X. Effect of thermal aging on uniaxial ratcheting behavior of vulcanized natural rubber. Polym. Test. 2018, 70, 102-110. [CrossRef]

12. Abuhasel, K.; Jeng, Y.T.; Munusamy, Y.; Kchaou, M.; Alquraish, M. Latex-based membrane for oily wastewater filtration: Study on the sulfur concentration effect. Appl. Sci. 2021, 11, 1779. [CrossRef]

13. Lu, J.; Gu, Y.; Chen, Y.; Yan, X.; Guo, Y.; Lang, W. Ultrahigh permeability of graphene-based membranes by adjusting D-Spacing with poly (ethylene imine) for the separation of dye wastewater. Sep. Purif. Tech. 2019, 210, 737-745. [CrossRef]

14. Zhao, Y.; Yu, W.; Li, R.; Xu, Y.; Liu, Y.; Sun, T.; Shen, L.; Lin, H. Effect field endowing the conductive polyvinylidene fluoride (PVDF)-graphene oxide (GO)-nickel (Ni) membrane with high-efficient performance for dye wastewater treatment. Appl. Surf. Sci. 2019, 483, 1006-1016. [CrossRef]

15. Zhao, C.; Xu, X.; Chen, J.; Wang, G.; Yang, F. Highly effective antifouling performance of PVDF/graphene oxide composite membrane in membrane bioreactor (MBR) system. Desalination 2014, 340, 59-66. [CrossRef]

16. Wu, W.; Zhang, X.; Qin, L.; Li, X.; Meng, Q.; Shen, C.; Zhang, G. Enhanced MPBR with polyvinylpyrrolidone-graphene oxide/PVDF hollow fiber membrane for efficient ammonia nitrogen wastewater treatment and highly-density Chlorella cultivation. Chem. Eng. J. 2020, 379, 122368. [CrossRef]

17. Nawaz, H.; Umar, M.; Ullah, A.; Razzaq, H.; Mahmood Zia, K.; Liu, X. Polyvinylidene fluoride nanocomposite super hydrophilic membrane integrated with polyaniline-graphene oxide nano fillers for treatment of textile effluents. J. Hazard. Mat. 2021, 403, 123587. [CrossRef] [PubMed]

18. Marjani, A.; Nakhjiri, A.T.; Adimi, M.; Jirandehi, H.F.; Shirazian, S. Effect of graphene oxide on modifying polyethersulfone membrane performance and its application in wastewater treatment. Sci. Rep. 2020, 10, 1-11. [CrossRef]

19. Alammar, A.; Park, S.H.; Williams, C.J.; Derby, B.; Szekely, G. Oil-in-water separation with graphene-based nanocomposite membranes for produced water treatment. J. Membr. Sci. 2020, 603, 118007. [CrossRef]

20. Abdalla, O.; Wahab, M.A.; Abdala, A. Mixed matrix membranes containing aspartic acid functionalized graphene oxide for enhanced oil-water emulsion separation. J. Environ. Chem. Eng. 2020, 8, 104269. [CrossRef]

21. Kazemi, F.; Jafarzadeh, Y.; Masoumi, S.; Rostamizadeh, M. Oil-in-water emulsion separation by PVC membranes embedded with GO-ZnO nanoparticles. J. Environ. Chem. Eng. 2021, 9, 104992. [CrossRef]

22. Moradi, R.; Karimi-Sabet, J.; Shariaty-Niassar, M.; Amini, Y. Air gap membrane distillation for enrichment of $\mathrm{H} 218 \mathrm{O}$ is isotopomers in natural water using poly(vinylidene) fluoride nanofibrous membrane. Chem. Eng. Proc. Intensif. 2016, 100, 26-36. [CrossRef]

23. Su, C.; Li, Y.; Cao, H.; Lu, C.; Li, Y.; Chang, J.; Duan, F. Novel PTFE hollow fibre membrane fabricated by emulsion electronspinning and sintering for membrane distillation. J. Memb. Sci. 2019, 583, 200-208. [CrossRef] 
24. Yu, L.; Kanezashi, M.; Nagasawa, H.; Tsuru, T. Phase inversion/sintering-induced porous ceramic microsheet membranes for high-quality separation of oily wastewater. J. Memb. Sci. 2020, 595, 117477. [CrossRef]

25. Bai, M.; Qiang, L.; Meng, M.; Li, B.; Wang, S.; Wu, Y.; Chen, L.; Dai, J.; Liu, Y.; Pan, J. Upper surface imprinted membrane prepared by magnetic guidance phase inversion method for highly efficient and selective separation of Artemisinin. Chem. Eng. J. 2021, 405, 126899. [CrossRef]

26. Liu, H.; Liao, X. The effect of fluorocarbon special surfactant (FS-30) additive on the phase inversion, morphology and separation performance of poly(vinylidene fluoride) (PVDF) membranes. Sep. Purif. Tech. 2019, 212, 619-631. [CrossRef]

27. Mashentseva, A.A.; Barsbay, M.; Aimanova, N.A.; Zdorovets, M.V. Application of silver-loaded composite track-etched membranes for photocatalytic decomposition of methylene blue under visible light. Membrane 2021, 11, 60. [CrossRef] [PubMed]

28. Pereao, O.; Uche, C.; Bublikov, P.S.; Bode-Aluko, C.; Rossouw, A.; Vinogradov, I.I.; Nechaev, A.N.; Opeolu, B.; Petrik, L. Chitosan/PEO nanofibers electrospun on metallized track-etched membranes: Fabrication and characterization. Mat. Today Chem. 2021, 20, 100416. [CrossRef]

29. Jiang, Y.; Zeng, Q.; Biswas, P.; Fortner, J.D. Graphene oxides as nanofillers in polysulfone ultrafiltration membranes: Shape matters. J. Memb. Sci. 2019, 581, 453-461. [CrossRef]

30. Abuabdou, S.M.A.; Bashir, M.J.K.; Aun, N.C.; Sethupathi, S.; Yong, W.L. Development of a novel polyvinylidene fluoride membrane integrated with palm oil fuel ash for stabilized landfill leachate treatment. J. Clean. Prod. 2021, 311, 127677. [CrossRef]

31. Huang, Y.; Huang, Q.; Liu, H.; Zhang, C.; You, Y.; Li, N.; Xiao, C. Preparation, characterization and applications of electrospun ultrafine fibrous PTFE porous membranes. J. Memb. Sci. 2017, 523, 317-326. [CrossRef]

32. Gao, J.; Wang, J.; Xu, Q.; Wu, S.; Chen, Y. Regenerated cellulose strongly adhered by supramolecular adhesive onto PVDF membrane for highly efficient oil/water separation. Green Chem. 2021, 23, 5633-5646. [CrossRef]

33. Wang, C.; Chi, H.; Zhang, F.; Wang, X.; Wang, Y.; Zhang, H.; Bai, Y.; Tan, Y.; Xu, K.; Wang, P. Superwettable porous spheres prepared by recyclable Pickering emulsion polymerization for multifarious oil/water separations. Green Chem. 2021, 23, $2372-2381$. [CrossRef]

34. Dacrory, S. Antimicrobial activity, DFT calculations and molecular docking of dialdehyde cellulose/graphene oxide film against Covid-19. J. Polym. Environ. 2021, 1-13. [CrossRef]

35. Bhadran, B.; Vijayan, D.; George, N.; Chandra, C.J.; Begum, P.S.; Jospeh, R. Reinforcing effect of organocly in nitrile rubber-effect of mill mixing and latex stage mixing. Appl. Clay Sci. 2018, 165, 91-102. [CrossRef]

36. Yong, T.J.; Munusamy, Y.; Ding, S.J.; Ismail, H. Fabrication of a novel latex-based membrane for oily wastewater filtration: Effect of degassing on the properties of membrane. Iran. Polym. J. 2021, 1-12. [CrossRef]

37. Yew, G.Y.; Tham, T.C.; Law, C.L.; Chu, D.T.; Orino, C.; Show, P.L. Emerging crosslinking techniques for glove manufacturers with improved nitrile glove properties and reduced allergic risks. Mater. Today Communi. 2019, 19, 39-50. [CrossRef]

38. Pourziad, S.; Omidkhah, M.R.; Abdollahi, M. Improved antifouling and self-cleaning ability of PVDF ultrafiltration membrane grafted with polymer brushes for oily water treatment. J. Indus. Eng. Chem. 2020, 83, 401-408. [CrossRef]

39. Valizadeh, S.; Naji, L.; Karimi, M. Controlling interlayer spacing of graphene oxide membrane in aqueous media using a biocompatible heterobifunctional crosslinker for Penicillin-G Procaine removal. Sep. Purif. Tech. 2021, 263, 118392. [CrossRef]

40. Junaidi, N.F.D.; Othman, N.H.; Shahruddin, M.Z.; Alias, N.H.; Marpani, F.; Lau, W.J.; Ismail, A.F. Fabrication and characterization of graphene oxide-polyethersulfone (GO-PES) composite flat sheet and hollow fiber membranes for oil-water separation. J. Chem. Technol. Biotechnol. 2020, 95, 1308-1320. [CrossRef]

41. Zhong, Y.; Mahmud, S.; He, Z.; Yang, Y.; Zhang, Z.; Guo, F.; Chen, Z.; Xiong, Z.; Zhao, Y. Graphene oxide modified membrane for highly efficient wastewater treatment by dynamic combination of nanofiltration and catalysis. J. Hazard. Mat. 2020, $397,122774$. [CrossRef] [PubMed]

42. Ansari, A.; Peña-Bahamonde, J.; Wang, M.; Shaffer, D.L.; Hu, Y. Polyacrylic acid-brushes tethered to graphene oxide membrane coating scaling and biofouling on reverse osmosis membranes. J. Memb. Sci. 2021, 630, 119308. [CrossRef]

43. Wang, L.; Zhang, J.; Sun, Y.; Zhang, T.; Wang, L.; Wang, J.; Liang, Y.; Hao, M.; Fu, Q. Green preparation and enhanced gas barrier property of rubber nanocomposite film based on graphene oxide-induced chemical crosslinking. Polymer 2021, $225,123756$. [CrossRef]

44. Vinayan, B.P.; Zhao-Karger, Z.; Diemant, T.; Chakravadhanula, V.S.K.; Schwarzburger, N.I.; Cambaz, M.A.; Behm, R.J.; Kübel, C.; Fichtner, M. Performance study of magnesium-sulfur battery using a graphene-based sulfur composite cathode electrode and a non-nucleophilic Mg electrolyte. Nanoscale 2015, 8, 3296-3306. [CrossRef] [PubMed]

45. Yang, Z.; Yuan, Z.; Shang, Z.; Ye, S. Multi-functional membrane based on montmorillonite/graphene oxide nanocomposites with high actuating performance and wastewater purification. Appl. Clay Sci. 2020, 197, 105781. [CrossRef]

46. Zhang, Y.; Cho, U.R. Enhanced thermo-physical properties of nitrile-butadiene rubber nanocomposites filled with simultaneously reduced and functionalized graphene oxide. Polym. Comp. 2018, 39, 3227-3235. [CrossRef]

47. Mensah, B.; Kim, S.; Arepalli, S.; Nah, C. A study of graphene oxide-reinforced rubber nanocomposites. J. Appl. Polym. Sci. 2014, 131, 40640. [CrossRef]

48. Wang, Z.; Yu, H.; Xia, J.; Zhang, F.; Li, F.; Xia, Y.; Li, Y. Novel GO-blended PVDF ultrafiltration membranes. Desalination 2012, 299, 50-54. [CrossRef]

49. Lawler, J. Incorporation of graphene-related carbon nanosheets in membrane fabrication for water treatment: A review. Membranes 2016, 6, 57. [CrossRef] 
50. Hussain, A.; Al-Yaari, M. Development of polymeric membranes for oil/water separation. Membranes 2021, 11, 42. [CrossRef]

51. Chen, A.S.C.; Flynn, J.T.; Cook, R.G.; Casaday, A.L. Removal of oil, grease, and suspended solids from produced water with ceramic crossflow microfiltration. SPE Prod. Eng. 1991, 6, 131-136. [CrossRef]

52. Amid, M.; Nabian, N.; Delavar, M. Fabrication of polycarbonate ultrafiltration mixed matrix membranes including modified halloysite nanotubes and graphene oxide nanosheets for olive oil/water emulsion separation. Sep. Purif. Technol. 2020, 251, 117332. [CrossRef]

53. Tanudjaja, H.J.; Hejase, C.A.; Tarabara, V.V.; Fane, A.G.; Chew, J.W. Membrane-based separation for oily wastewater: A practical perspective. Water Res. 2019, 156, 347-365. [CrossRef]

54. Heylen, C.; Oliveira Aguiar, A.; String, G.; Domini, M.; Goff, N.; Murray, A.; Asatekin, A.; Lantagne, D. Laboratory efficacy of locally available backwashing methods at removing fouling in hollow-fiber membrane filters used for household water treatment. Membranes 2021, 11, 375. [CrossRef] [PubMed]

55. Lin, J.C.-T.; Lee, D.-J.; Huang, C. Membrane fouling mitigation: Membrane cleaning. Sep. Sci. Tech. 2010, 45, 858-872. [CrossRef]

56. An, Y.; Wu, B.; Wong, F.S.; Yang, F. Post-treatment of upflow anaerobic sludge blanket effluent by combining the membrane filtration process: Fouling control by intermittent permeation and air sparging. Water Environ. J. 2010, 24, 32-38. [CrossRef]

57. Ruiz, L.M.; Perez, I.; Gómez, A.; Letona, A.; Gómez, M.A. Ultrasonic irradiation for ultrafiltration membrane cleaning in MBR systems: Opearational conditions and consequences. Water Sci. Tech. 2017, 75, 802-812. [CrossRef] [PubMed]

58. Arefi-Oskoui, S.; Khataee, A.; Safarpour, M.; Orooji, Y.; Vatanpour, V. A review on the applications of ultrasonic technology in membrane bioreactors. Ultrason. Sonochem. 2019, 58, 104633. [CrossRef] [PubMed]

59. Gul, A.; Hruza, J.; Yalcinkaya, F. Fouling and chemical cleaning of microfiltration membranes: A mini-review. Polymers 2021, 13, 846. [CrossRef] [PubMed]

60. AlSawaftah, N.; Abuwatfa, W.; Darwish, N.; Husseini, G. A comprehensive review on membrane fouling: Mathematical modelling, prediction, diagnosis and mitigation. Water 2021, 13, 1327. [CrossRef]

61. Ding, W.; Chen, M.; Zhou, M.; Zhong, Z.; Cui, Z.; Xing, W. Fouling behavior of poly(vinylidene fluoride) (PVDF) ultrafiltration membrane by polyvinyl alcohol (PVA) and chemical cleaning method. Chin. J. Chem. Eng. 2020, 28, 3018-3026. [CrossRef]

62. Ren, L.; Yu, S.; Yang, H.; Li, L.; Cai, L.; Xia, Q.; Shi, Z.; Liu, G. Chemical cleaning reagent of sodium hypochlorite eroding polyvinylidene fluoride ultrafiltration membranes: Aging pathway, performance decay and molecular mechanism. J. Memb. Sci. 2021, 625, 119141. [CrossRef] 